\title{
MEASURING STUDENT AND STAFF SATISFACTION WITH THE UNIVERSITY FACILITIES
}

\author{
Abdelkader Derbali and Ahmed K Elnagar
}

\begin{abstract}
Today in the world, service companies are always concerned with the quality of services, which is used by many universities to increase their competitiveness under conditions of fierce competition. Universities, therefore, think of students as their main clients, as well as seek teachers and administrators' satisfaction by improving the quality of their services (Nguyen, 2012). The purpose of this article is to evaluate the quality of services offered by the Community College in Taibah University to its students and staff. The data are collected by questioning a sample of 281 respondents in the Community College at Taibah University during the 2018-2019 academic year. A descriptive analysis is used to define the variables of our study, and the principal component analysis (PCA) is applied to determine the contribution of each variable as a factor that affects the respondents' preferences. The principal component analysis method captures the key variables of the staff satisfaction at the Community College in Taibah University regarding the services provided. The empirical findings of this study let the authors show that the student and staff satisfaction of the Community College in Taibah University is related to certain factors which constitute a necessity for respondents of both genders. These results serve as benchmarks to allow managers of the institution to improve the quality of their services.
\end{abstract}

Keywords: satisfaction, principal component analysis, community college, quality of services JEL Classification: L84, J28 


\section{Authors:}

Abdelkader Derbali

Department of Administrative and Financial Sciences and Techniques, Community College, Taibah University, Saudi Arabia; Department of Management Sciences, Higher Institute of Informatics and Management of Kairouan, Kairouan University, Tunisia

Email: derbaliabdelkader@outlook.fr.*Corresponding author

https://orcid.org/0000-0003-4098-3120

\section{Ahmed K Elnagar}

Department of Administrative and Financial Sciences and Techniques, Community College, Taibah University, Saudi Arabia; Suez Canal University, Egypt

Email: ahmed karam@tourism.suez.edu.eg

https://orcid.org/0000-0003-4098-3120

Citation: Derbali, A., \& Elnagar, A.K. (2020). Measuring Student and Staff Satisfaction with the University Facilities. Virtual Economics, 3(3), 25-52. https://doi.org/10.34021/ve.2020.03.03(2)

Received: April 12, 2020. Revised: June 6, 2020. Accepted: July 9, 2020.

(C) Author(s) 2020. Licensed under the Creative Commons License - Attribution 4.0 International (CC BY 4.0) 


\section{Introduction}

Quality is seen as a determinant of competitiveness and a source of sustainable competitive advantage (Moore, 1987; Lewis, 1989). For higher education, quality is a determining factor in satisfaction of students, who are the main consumer. Some authors consider that satisfaction with the education system is the most important objective that the educational establishment is to aim for.

In the university environment, student satisfaction is strongly linked to the quality of higher education services and the learning environment. It is considered by Cronin and Taylor (1992), Clemes et al. (2008; 2010), Omar et al. (2009) as the source of efficiency in the organization's communication policy. This keeps the image of the university and increases its students' satisfaction rate with the service provided.

The concept of satisfaction, developed particularly in the context of service activities, has been the subject of much research in management sciences. The analysis of the individual consumer satisfaction (transactional or relational) by studying their behaviour has become an essential research pole (Moutte, 2007; Madden, 2017; Tran et al., 2020; Alsulami and Makhbul, 2020).

Compared with the commercial or industrial sector, previous research shows that quality service in higher education is still a major concern (Sultan and Wong 2010). It was since 1980s that higher education has paid more attention to quality service. This improvement has been due to the intention of educational institutions to meet their consumers' demands.

Higher education is one of the main drivers of economic development. Teaching excellence is a key to strong and growing economy. It consists of providing quality training that improves knowledge, and creates prerequisites for students to acquire adequate profiles and to become more competitive in the job market, which is constantly changing with technology, globalization, and demographics that influence the country.

The University in general is obliged to cope with an increasingly globalized environment and international competitiveness, which is now based on innovation and competence in new technologies. As a result, it must adopt effective structures and strategies to meet the demands of its students, who are the main consumer of the university services.

In this context, student satisfaction is strongly linked to the quality of higher education services and the learning environment. It is considered by Cronin and Taylor (1992), Clemes et al. (2008), and Omar et al. (2009) as the source of efficiency in the organization's communication policy, which preserves the image of the university and increases the satisfaction rate of its students with the services provided. According to the analysis by Alves and Raposo (2007), satisfaction contributes significantly to the relationships between students and educational institutions. This explains the causal relationship between the quality of the service offered in the educational establishment and the students' satisfaction (Cronin et al., 2000). Some 
authors consider that the satisfaction with the education system is the most important objective that the educational establishment is to aim for.

The quality of service becomes a key factor of competitiveness. As the level of customer demand increases with the level of competition becoming more intense, quality dominates economic profitability. Therefore, it seems particularly important to understand at best what the expectations and perceptions of customers are if we want to aim at their satisfaction.

As far as the higher education sector in Saudi Arabia is concerned, the competition is intensifying, and staff are constantly expanding the range of providers. This competitiveness is due to an uncontrolled and unbalanced quantitative growth of the workforce. The fragmentation of supply into a multitude of small establishments is followed by an increase in demand as students may choose to keep or leave their institutions at the end of each year or academic cycle. It is, therefore, important to know the determinants and the result of customer satisfaction, which, up to now, have remained a major challenge and a critical management problem (Balemba, 2013).

In this paper, we try to examine empirically the satisfaction of staff (teachers, administrators and students) of the Community College at Taibah University in Saudi Arabia during the 20182019 academic year. This satisfaction is related the service quality offered by the Community College. In this context, we used a questionnaire addressed to teachers, administrators, and students. Two approaches were applied to analyse the empirical results of this survey. Firstly, we used a descriptive analysis based on studying the distribution of respondents according to their responses using the number of individuals and frequencies. Secondly, we applied the Principal Component Analysis (PCA) method to capture the determinants of the services quality provided by the Community College at Taibah University to its staff during the 20182019 academic year.

To achieve the purpose set, this paper is organized as follows: Section 2 presents a literature review. In Section 3, we outline the econometric methodology applied and look at the data. Section 4 is devoted to the presentation of empirical results. Finally, Section 5 summarises the conclusions.

\section{Literature Review}

\subsection{Consumer Satisfaction}

The concept of satisfaction comes from two Latin words: 'satis' and 'facere'. These terms mean respectively 'enough' and 'do'. Explicitly, the notion of satisfaction means 'providing what is sought to the point where it is enough' (Vanhamme, 2001). Nowadays, however, the definition of consumer satisfaction differs a lot, according to the researchers. This is the very explanatory basis of its measurement by several methods (Park, 2007). 
According to microeconomic approaches, consumer satisfaction is the result of the partial or complete destruction of a commodity (or even commodities). The level of satisfaction achieved and the quantity of several goods consumed are related to the utility function. It is, therefore, appropriate to note that the level of consumer satisfaction is a function of the quantity of one or more goods consumed. It is the optics of goods.

From a perspective of goods and services, the notion of satisfaction is the subject of a topic that has even been considered the cornerstone of marketing. Satisfaction would, therefore, be appreciated in three ways: satisfaction because of services, satisfaction as benchmarking and satisfaction as an assessment of the quality of services (Cantin and Rocheleau, 2006).

In the marketing literature on services, many studies based on Wolfinbarger and Gilly have examined the link between satisfaction and the quality of services (Bressolles et al., 2007). In this context, the notion of satisfaction is a concept with uncertain limits because some authors call it a feeling, a positive emotional state, and a psychological state (Jouandeau, 2004).

Satisfaction is defined as an evaluation of surprise inherent in the acquisition of a product and/or a consumption experience. In other words, satisfaction is a psychological state of a client that results from the comparison between his expectations of a product or service, and his feelings after purchase and consumption of a product. This state implies that consumption emanates only a positive feeling, but also neutral and negative feelings.

A positive feeling means satisfaction, a neutral feeling means indifference, and a negative feeling means dissatisfaction (Bressolles et al., 2007; Ilunga, 2011). It follows that satisfaction results from the gap between expectations and perceived quality (Le Roy, 2004). Here, consumer satisfaction is, therefore, induced by the quality of goods or services consumed.

These two components (expectations and perceived quality) show that consumer satisfaction can be divided into two stages based on the moment of purchase. According to Oliver, this is the pre-purchase process and the post-purchase process. In the pre-purchase process, the consumer is waiting for the performance of a product based on various information. Then, in the after-purchase process, he judges whether his expectations and needs, formed before the purchase, are well gratified. Then he makes his judgment on satisfaction/dissatisfaction (Park, 2007).

\subsection{Determinants of Satisfaction}

To learn the customers' opinion on the company services, there arises the question of which criteria this evaluation should be based on. It is important to know what must be measured, i.e. to identify the services offered by the organization. This is the stage of identifying the elements of the service which shape different opinions of customers. These elements are grouped under general themes called "dimensions". Other authors prefer the terminology of "engines", "determinants", "key factors", or "components" (Tremblay, 2006). The terms 
"dimensions and/or components", "determinants" and/or "factors" are retained as part of this research.

\subsection{Importance of Customer Surveys}

In the Direct Marketing Journal, Charles Gengler says, "Customer satisfaction surveys are not just a tool for measuring customer behaviour but they can also be used as a proactive CRM tool." Regular monitoring of customer satisfaction levels and a corresponding response can increase loyalty and retention levels. Below, the paragraphs highlight the importance of the most consistent benefits of using customer surveys to create a regular dialogue with consumers:

- Re-deploy resources to address the most important issues: Surveys can quickly highlight the most important issues for clients, employees or the management team, on which the team and the company should focus.

- Improve the quality of service: A customer satisfaction survey can provide a more complete picture of overall service delivery, not just problems that require a "quick response". This is one of the crucial elements of the process of continuous improvement of services.

- Demonstrate commitment to customers: Even if customers and prospects never respond to polls, asking for their opinion helps to score points and earn their respect.

- Offer an escape to customers: Surveys provide disgruntled customers with a way out of negative feelings while allowing the company to obtain key data to help correct the situation.

- Measure the performance of the team: By associating surveys with individual transactions or activities, and by collecting these data on a regular basis, the company can gain a reliable insight into the performance of its team as it interacts with customers and prospects.

- Encourage new orders: While it is common to see customers ordering services or products only once, a survey can usually allow the company to remember customers' "good memories" and encourage them to place new orders or to give clues as to the potential needs that the company should satisfy.

- Collect information about the competition: Simple market surveys can give the company access to true business intelligence in terms of its positioning as well as its products and services compared to competitors.

- Get feedback on new products and services: It is question of why the new offer of the company knows a success or a failure. In other words, it is important to identify simple actions to take in order to achieve important improvements. A well-crafted survey allows the company to address these concerns.

- Inform the product and service development department: A prospect-focused survey will help the company anticipate market needs and will give it a better overview of the service offerings it should consider developing in the future.

- Prioritization of development resources: It is a question of knowing better to prioritize the resources for developing the products and services of the company by carrying out a survey intended for both customers and prospects. 


\section{Data and Methodology}

\subsection{Data Collection Technique}

Data collection techniques focus on qualitative and quantitative studies. The qualitative studies focus on the questionnaires sent to Community College staff of both genders; while, quantitative studies cover the pre-survey, the determination of the sample size and the actual survey.

For example, the interview was conducted with 281 respondents in the Community College at Taibah University during the 2018-2019 academic year. However, referring to the theoretical foundations, two criteria are necessary to determine the individuals to be interviewed (Rorer, 1983): the semantic saturation criterion, for which it is useless to proceed to new interviews since the latter no longer brings new information compared to the previous ones; and the theoretical saturation criterion, according to which it is no longer necessary to conduct new interviews once the entire theoretical field to be covered is effective.

The questionnaire is sent to Community College staff at Taibah University during the academic year 2018-2019 to be answered by teachers (39), administrators (31) and students (211).

\subsection{Data Processing Technique}

The data are processed by SPSS 24 . However, the results are analysed based on some previous studies by such authors as: (Tremblay and Beauregard, 2006; Tremblay, 2006; Balemba, 2013; Ilunga, 2011; Fouquereau et al., 2006; Nguyen, 2012; Gonzalez, 2004; Park, 2007; Sempels, 2005).

\section{Data Collection Technique:}

These techniques focus on qualitative and quantitative studies. The qualitative studies focus on the questionnaires sent to Community College staff of both genders; while, quantitative studies cover the pre-survey, the determination of the sample size and the actual survey.

In our case, we use an interview for a sample composed of 281 Community College respondents at Taibah University through the 2018-2019 academic year. Nevertheless, regarding the hypothetical fundamentals, two principles are required for the purpose of the population to be questioned: the semantic capacity principle and the theoretic capacity criterion. The questionnaire is sent to the Community College staff at Taibah University during the academic year 2018-2019 to be answered by teachers (39), administrators (31) and students (211).

Data Processing Technique: 
The data processing technique is based on a descriptive analysis and the method of analysis by the main component. Principal Component Analysis (PCA), or the application domain Karhunen-Loève Transformation (KLT), is a method of the family of data analysis and, more generally, of multivariate statistics, which consists of transforming linked variables (called "correlated" in statistics) into new uncorrelated variables. These new variables are called "principal components", or main axes. It allows the practitioner to reduce the number of variables and make the information less redundant.

The contributions of each variable to forming the principal components are defined in the same way as those of the individuals. They are calculated as follows:

$$
\text { Contribution of each variable }=\frac{\text { Factor }_{i}^{2}}{\text { Own Values }}
$$

The questionnaire differs according to the nature of the Community College respondents of both genders, male and female. Tables 1, 2, and 3 present respectively the different questions addressed to teachers, students, and administrators. Table 1 presents the questions and their items addressed to the academic faculty of both genders, male and female, in the Community College at Taibah University during the academic year 2018-2019. Table 2 presents the questions and their items addressed to the students of both genders, male and female, in the Community College at Taibah University during the academic year 2018-2019. Table 3 presents the questions and their items addressed to the administrative personnel of both genders, male and female, in the Community College at Taibah University during the academic year 2018-2019.

\section{Empirical Results}

\subsection{Descriptive Analysis}

In this part, we use a descriptive analysis to present the repartition of the employed sample. The aim of this questionnaire is to measure the quality level of services provided at the Community College at Taibah University in Medina. This questionnaire was sent electronically to all members of the Community College at Taibah University: administrative staff, faculty, and students.

Table 4 presents personal information of the academic staff of both genders, male and female. As for the distribution of faculty members by nationality, we note that in the student segment, $36 \%$ are Saudi and the rest $64 \%$ are foreigners. Among the female respondents, $59 \%$ are Saudis and the remaining $41 \%$ are non-Saudian. With regard to the distribution of faculty members by degree, we note that they consist of two members at the rank of a teaching assistant, 4 members at the rank of a lecturer, 14 members at the rank of an assistant professor and two members at the rank of an associate professor. As for the female faculty members, we note that they comprise 4 members at the rank of a teaching assistant, 6 members at the rank of a 
lecturer, 6 members at the rank of an assistant professor and one member at the rank of an associate professor. Most academic staff have between 5 and 10 years of experience for both genders: male (64\%) and female (46\%).

Table 1. Selected Questions and Items in the Questions Addressed to the Academic Staff

\begin{tabular}{|c|c|c|}
\hline Variables & Items & Code \\
\hline \multirow{4}{*}{$\begin{array}{c}\text { Personal } \\
\text { information }\end{array}$} & Nationality & 1 \\
\hline & Degree & 2 \\
\hline & Years of Experience & 3 \\
\hline & Work \Position & 4 \\
\hline \multirow{10}{*}{$\begin{array}{l}\text { Statements } \\
\text { related to the } \\
\text { material supply }\end{array}$} & The College provides classrooms suitable for lectures & 5 \\
\hline & Parking is available next to the college & 6 \\
\hline & The number of devices in laboratories proportional to the number of students & 7 \\
\hline & College offers scientific (electronic paper) books & 8 \\
\hline & Facilities for students with special needs available at the college & 9 \\
\hline & Plates and benchmarks installed to facilitate access to the various sections of the college & 10 \\
\hline & There is a website for a privileged college on the internet & 11 \\
\hline & Highly-efficient administrative body available at the college & 12 \\
\hline & Appropriate recreational activities available at the college & 13 \\
\hline & The college is dedicated to offer workshops training courses at the College Halls & 14 \\
\hline \multirow{5}{*}{$\begin{array}{l}\text { Phrases related to } \\
\text { the dependency } \\
\text { dimension }\end{array}$} & The College organizes the design of new students' programs & 15 \\
\hline & College offers students an academic advisor to help throughout the study period & 16 \\
\hline & The College offers special assistance for talented students & 17 \\
\hline & Students are encouraged to participate in the activities of field experience & 18 \\
\hline & The curriculum is flexible & 19 \\
\hline \multirow{5}{*}{$\begin{array}{l}\text { Statements } \\
\text { related to the } \\
\text { reliability } \\
\text { dimension }\end{array}$} & Relationships between faculty and administrative staff and students are based on trust and respect & 20 \\
\hline & Students evaluate the performance of justice & 21 \\
\hline & The college is dedicated to the students with the concepts of research ethics and scientific integrity & 22 \\
\hline & The college keeps information about beneficiaries confidential & 23 \\
\hline & I feel proud of belonging to the college & 24 \\
\hline \multirow{5}{*}{$\begin{array}{l}\text { Aspects of the } \\
\text { social empathy } \\
\text { dimension }\end{array}$} & Faculty shows student assessment procedures at the beginning of teaching courses & 25 \\
\hline & The communication between faculty and students is effective & 26 \\
\hline & The college provides communication channels through which students can express any problem they face & 27 \\
\hline & The college is keen to identify student needs periodically & 28 \\
\hline & The Department of the college is interested in organizing timetable in the interest of students & 29 \\
\hline \multirow{3}{*}{$\begin{array}{l}\text { Phrases related to } \\
\text { the dimension of } \\
\text { enthusiasm }\end{array}$} & I feel the enthusiasm in doing my job & 30 \\
\hline & I accept the challenge in the tasks that I perform & 31 \\
\hline & I enjoy high flexibility in my job & 32 \\
\hline \multirow{3}{*}{$\begin{array}{l}\text { Phrases related to } \\
\text { the dimension of } \\
\text { dedication }\end{array}$} & I am proud of the work I do & 33 \\
\hline & I feel that the work I do has value and purpose & 34 \\
\hline & I have enough perseverance to work even in the worst circumstances & 35 \\
\hline
\end{tabular}




\begin{tabular}{ccc}
\hline \multirow{2}{*}{\begin{tabular}{c} 
Phrases related to \\
the absorption \\
\cline { 2 - 3 }
\end{tabular}} & I am enjoying my work performance & 36 \\
\cline { 2 - 3 } & I have spent a long time in my performance & 37 \\
\hline
\end{tabular}

Source: developed by the authors.

Table 2. Selected Questions and Items of the Questions Addressed to Students

\begin{tabular}{|c|c|c|}
\hline Variables & Items & Code \\
\hline \multirow{5}{*}{ Personal information } & Type & 1 \\
\hline & Nationality & 2 \\
\hline & Department & 3 \\
\hline & Study level & 4 \\
\hline & Cumulative average & 5 \\
\hline \multirow{10}{*}{$\begin{array}{l}\text { Statements relating to the } \\
\text { material elements of the } \\
\text { concrete }\end{array}$} & The college provides classrooms suitable for lectures & 6 \\
\hline & Parking is available next to the college & 7 \\
\hline & The number of devices in laboratories is proportional to the number of students & 8 \\
\hline & The College offers scientific (electronic paper) books & 9 \\
\hline & Facilities for students with special needs available at the college & 10 \\
\hline & Plates and benchmarks installed to facilitate access to the various sections of the college & 11 \\
\hline & There is a website for a privileged college on the internet & 12 \\
\hline & Highly-efficient administrative body available at the college & 13 \\
\hline & Appropriate recreational activities available at the college & 14 \\
\hline & The college is dedicated to offer workshops training courses at the College Halls & 15 \\
\hline \multirow{5}{*}{$\begin{array}{l}\text { Aspects of the social } \\
\text { empathy dimension }\end{array}$} & Faculty shows student assessment procedures at the beginning of teaching courses & 16 \\
\hline & The communication between faculty and students is effective & 17 \\
\hline & $\begin{array}{l}\text { The college provides communication channels through which students can express any } \\
\text { problem they face }\end{array}$ & 18 \\
\hline & The college is keen to identify student needs periodically & 19 \\
\hline & $\begin{array}{c}\text { The Department of the college is interested in organizing timetable in the interest of } \\
\text { students }\end{array}$ & 20 \\
\hline \multirow{5}{*}{$\begin{array}{l}\text { Phrases related to the } \\
\text { responsiveness dimension }\end{array}$} & The faculty members are willing to answer all the students' questions & 21 \\
\hline & The college staff is highly motivated to serve the students & 22 \\
\hline & The college accurately informs beneficiaries of the dates of service & 23 \\
\hline & The team is interested in meeting the beneficiaries' requests immediately & 24 \\
\hline & The Advisory Council responds the students' needs quickly & 25 \\
\hline \multirow{5}{*}{$\begin{array}{l}\text { Statements related to the } \\
\text { reliability dimension }\end{array}$} & $\begin{array}{l}\text { Relationships between faculty and administrative staff and students are based on trust and } \\
\text { respect }\end{array}$ & 26 \\
\hline & Students evaluate the performance of justice & 27 \\
\hline & $\begin{array}{l}\text { The college is dedicated to the students with the concepts of research ethics and scientific } \\
\text { integrity }\end{array}$ & 28 \\
\hline & The college keeps information about beneficiaries confidential & 29 \\
\hline & I feel proud of belonging to the college & 30 \\
\hline
\end{tabular}

Source: developed by the authors. 
Table 3. Selected Questions and Items of the Questions Addressed to the Administrative Staff.

\begin{tabular}{|c|c|c|}
\hline Variables & Items & Code \\
\hline \multirow{2}{*}{ Personal information } & Nationality & 1 \\
\hline & Years of Experience & 2 \\
\hline \multirow{10}{*}{$\begin{array}{l}\text { Statements related to the } \\
\text { material supply }\end{array}$} & The College provides classrooms suitable for lectures & 3 \\
\hline & Parking is available next to the college & 4 \\
\hline & The number of devices in laboratories proportional to the number of students & 5 \\
\hline & College offers scientific (electronic paper) books & 6 \\
\hline & Facilities for students with special needs available at the college & 7 \\
\hline & Plates and benchmarks installed to facilitate access to the various sections of the college & 8 \\
\hline & There is a website for a privileged college on the internet & 9 \\
\hline & Highly-efficient administrative body available at the college & 10 \\
\hline & Appropriate recreational activities available at the college & 11 \\
\hline & The college is dedicated to offer workshops training courses at the College Halls & 12 \\
\hline \multirow{5}{*}{$\begin{array}{l}\text { Phrases related to the } \\
\text { responsiveness dimension }\end{array}$} & The faculty members are willing to answer all the students' questions & 13 \\
\hline & The college staff is highly motivated to serve the students & 14 \\
\hline & The college accurately informs beneficiaries of the dates of service & 15 \\
\hline & The team is interested in meeting the beneficiaries' requests immediately & 16 \\
\hline & The Advisory Council responds the students' needs quickly & 17 \\
\hline \multirow{5}{*}{$\begin{array}{l}\text { Statements related to the } \\
\text { reliability dimension }\end{array}$} & $\begin{array}{l}\text { Relationships between faculty and administrative staff and students are based on trust and } \\
\text { respect }\end{array}$ & 18 \\
\hline & Students evaluate the performance of justice & 19 \\
\hline & $\begin{array}{l}\text { The college is dedicated to the students with the concepts of research ethics and scientific } \\
\text { integrity }\end{array}$ & 20 \\
\hline & The college keeps information about beneficiaries confidential & 21 \\
\hline & I feel proud of belonging to the College & 22 \\
\hline \multirow{3}{*}{$\begin{array}{l}\text { Phrases related to the } \\
\text { dimension of enthusiasm }\end{array}$} & I feel the enthusiasm in doing my job & 23 \\
\hline & I accept the challenge in the tasks that I perform & 24 \\
\hline & I enjoy high flexibility in my job & 25 \\
\hline \multirow{3}{*}{$\begin{array}{l}\text { Phrases related to the } \\
\text { dimension of dedication }\end{array}$} & I am proud of the work I do & 26 \\
\hline & I feel that the work I do has value and purpose & 27 \\
\hline & I have enough perseverance to work even in the worst circumstances & 28 \\
\hline \multirow{3}{*}{$\begin{array}{l}\text { Phrases related to the } \\
\text { absorption dimension }\end{array}$} & I am enjoying my work performance & 29 \\
\hline & I have spent a long time in my performance & 30 \\
\hline & I feel happy to do double work & 31 \\
\hline
\end{tabular}

Source: developed by the authors.

Table 4. Descriptive Statistics for Academic Staff.

\begin{tabular}{|c|c|c|c|c|}
\hline Gender & $\begin{array}{c}\text { Personal } \\
\text { information }\end{array}$ & Items & $\begin{array}{l}\text { Number of } \\
\text { individuals }\end{array}$ & Frequency \\
\hline \multirow{3}{*}{ Male } & \multirow{4}{*}{ Nationality } & Saudi & 8 & $36 \%$ \\
\hline & & Non-Saudi & 14 & $64 \%$ \\
\hline & & Total & 22 & $100 \%$ \\
\hline Female & & Saudi & 10 & $59 \%$ \\
\hline
\end{tabular}




\begin{tabular}{|c|c|c|c|c|}
\hline & & Non-Saudi & 7 & $41 \%$ \\
\hline & & Total & 17 & $100 \%$ \\
\hline \multirow{6}{*}{ Male } & \multirow{12}{*}{ Degree } & Professor & 0 & $0 \%$ \\
\hline & & Associate professor & 2 & $9 \%$ \\
\hline & & Assistant professor & 14 & $64 \%$ \\
\hline & & Lecturer & 4 & $18 \%$ \\
\hline & & Teaching Assistant & 2 & $9 \%$ \\
\hline & & Total & 22 & $100 \%$ \\
\hline \multirow{6}{*}{ Female } & & Professor & 0 & $0 \%$ \\
\hline & & Associate professor & 1 & $6 \%$ \\
\hline & & Assistant professor & 6 & $35 \%$ \\
\hline & & Lecturer & 6 & $35 \%$ \\
\hline & & Teaching Assistant & 4 & $24 \%$ \\
\hline & & Total & 17 & $100 \%$ \\
\hline \multirow{5}{*}{ Male } & \multirow{10}{*}{ Years of Experience } & From 1 year to 5 years & 2 & $9 \%$ \\
\hline & & From 5 to less than 10 years & 14 & $64 \%$ \\
\hline & & From 10 to less than 15 years & 5 & $22.5 \%$ \\
\hline & & From 15 years and more & 1 & $4.5 \%$ \\
\hline & & Total & 22 & $100 \%$ \\
\hline \multirow{5}{*}{ Female } & & From 1 year to 5 years & 4 & $24 \%$ \\
\hline & & From 5 to less than 10 years & 8 & $46 \%$ \\
\hline & & From 10 to less than 15 years & 2 & $12 \%$ \\
\hline & & From 15 years and more & 3 & $18 \%$ \\
\hline & & Total & 17 & $100 \%$ \\
\hline \multirow{3}{*}{ Male } & \multirow{6}{*}{ Work \Position } & Academic only & 17 & $77 \%$ \\
\hline & & Academic and Administrative & 5 & $23 \%$ \\
\hline & & Total & 22 & $100 \%$ \\
\hline \multirow{3}{*}{ Female } & & Academic only & 10 & $59 \%$ \\
\hline & & Academic and Administrative & 7 & $41 \%$ \\
\hline & & Total & 17 & $100 \%$ \\
\hline
\end{tabular}

Source: developed by the authors.

Table 5 shows the personal information of the academic staff of both genders, male and female. As for the distribution of students by nationality, we note that all students are of Saudian nationality. Among the males, $56 \%$ are from Department of Administrative and Financial Sciences and Techniques and the remaining $44 \%$ are from the Department of Computer Sciences and Information. Among female respondents, 34\% are from Department of Administrative and Financial Sciences and Techniques and the remaining $66 \%$ are from the Department of Computer Sciences and Information. 54\% of the male students are in the first study level, while the female respondents are in the third study level.

Table 5. Descriptive Statistics for Students

\begin{tabular}{|c|c|c|c|c|}
\hline Part & $\begin{array}{c}\text { Personal } \\
\text { information }\end{array}$ & Items & $\begin{array}{l}\text { Number of } \\
\text { individuals }\end{array}$ & Frequency \\
\hline \multirow{3}{*}{ Male } & \multirow{6}{*}{ Nationality } & Saudi & 78 & $100 \%$ \\
\hline & & Non-Saudi & 0 & $0 \%$ \\
\hline & & Total & 78 & $100 \%$ \\
\hline \multirow{3}{*}{ Female } & & Saudi & 134 & $100 \%$ \\
\hline & & Non-Saudi & 0 & $0 \%$ \\
\hline & & Total & 134 & $100 \%$ \\
\hline \multirow{3}{*}{ Male } & \multirow{3}{*}{ Department } & $\begin{array}{l}\text { Department of Administrative and Financial Sciences and } \\
\text { Techniques }\end{array}$ & 44 & $56 \%$ \\
\hline & & Department of Computer Sciences and Information & 34 & $44 \%$ \\
\hline & & Department of Humanities and techniques & 0 & $0 \%$ \\
\hline
\end{tabular}




\begin{tabular}{|c|c|c|c|c|}
\hline & & Total & 78 & $100 \%$ \\
\hline \multirow{4}{*}{ Female } & & $\begin{array}{l}\text { Department of Administrative and Financial Sciences and } \\
\text { Techniques }\end{array}$ & 46 & $34 \%$ \\
\hline & & Department of Computer Sciences and Information & 88 & $66 \%$ \\
\hline & & Department of Humanities and techniques & 0 & $0 \%$ \\
\hline & & Total & 134 & $100 \%$ \\
\hline \multirow{5}{*}{ Male } & \multirow{10}{*}{ Study level } & First & 42 & $54 \%$ \\
\hline & & Second & 4 & $5 \%$ \\
\hline & & Third & 26 & $33 \%$ \\
\hline & & Fourth & 6 & $8 \%$ \\
\hline & & Total & 78 & $100 \%$ \\
\hline \multirow{5}{*}{ Female } & & First & 36 & $26 \%$ \\
\hline & & Second & 0 & $0 \%$ \\
\hline & & Third & 88 & $66 \%$ \\
\hline & & Fourth & 10 & $8 \%$ \\
\hline & & Total & 134 & $100 \%$ \\
\hline \multirow{5}{*}{ Male } & \multirow{10}{*}{$\begin{array}{l}\text { Cumulative } \\
\text { average }\end{array}$} & Excellent A & 36 & $46 \%$ \\
\hline & & Very good B & 22 & $28 \%$ \\
\hline & & Good C & 18 & $23 \%$ \\
\hline & & Acceptable D & 2 & $3 \%$ \\
\hline & & Total & 78 & $100 \%$ \\
\hline \multirow{5}{*}{ Female } & & Excellent $\mathrm{A}$ & 84 & $63 \%$ \\
\hline & & Very good B & 34 & $25 \%$ \\
\hline & & Good C & 14 & $10 \%$ \\
\hline & & Acceptable D & 2 & $2 \%$ \\
\hline & & Total & 134 & $100 \%$ \\
\hline
\end{tabular}

Source: developed by the authors.

Table 6 summarizes the personal information of the administrative staff of both genders, male and female. As for the distribution of administrative personnel by nationality, we conclude that they all are Saudian of both genders, male and female. Most academic staff of both genders, male and female, have between 1 and 10 years of experience; male: $50 \%$ - between 1 and 5 years and $50 \%$ - between 5 and 10 years and female: $45 \%$ - between 1 and 5 years and $55 \%$ - between 5 and 10 years.

Table 6. Descriptive Statistics for Administrative Personals

\begin{tabular}{|c|c|c|c|c|}
\hline Part & Personal information & Items & $\begin{array}{l}\text { Number of } \\
\text { individuals }\end{array}$ & Frequency \\
\hline \multirow{3}{*}{ Male } & \multirow{6}{*}{ Nationality } & Saudi & 10 & $100 \%$ \\
\hline & & Non-Saudi & 0 & $0 \%$ \\
\hline & & Total & 10 & $100 \%$ \\
\hline \multirow{3}{*}{ Female } & & Saudi & 20 & $100 \%$ \\
\hline & & Non-Saudi & 0 & $0 \%$ \\
\hline & & Total & 20 & $100 \%$ \\
\hline \multirow{4}{*}{ Male } & \multirow{4}{*}{ Years of Experience } & From 1 year to 5 years & 5 & $50 \%$ \\
\hline & & From 5 to less than 10 years & 5 & $50 \%$ \\
\hline & & From 10 to less than 15 years & 0 & $0 \%$ \\
\hline & & From 15 years and more & 0 & $0 \%$ \\
\hline
\end{tabular}




\begin{tabular}{|c|c|c|c|}
\hline & Total & 10 & $100 \%$ \\
\hline & From 1 year to 5 years & 9 & $45 \%$ \\
\hline & From 5 to less than 10 years & 11 & $55 \%$ \\
\hline \multirow[t]{3}{*}{ Female } & From 10 to less than 15 years & 0 & $0 \%$ \\
\hline & From 15 years and more & 0 & $0 \%$ \\
\hline & Total & 20 & $100 \%$ \\
\hline
\end{tabular}

Source: developed by the authors.

\subsection{The Results of PCA}

The principal components analysis makes it possible to answer three main questions namely: Are the data factorizable? How many factors are there to remember? How should the results be interpreted?

\subsubsection{Academic Faculty}

\subsubsection{Academic Faculty (A Male Segment)}

Tables 7-13 present the results of the PCA relative to the questions and their items addressed to the male academic faculty in the Community College at Taibah University during the academic year 2018-2019. In these Tables (7-13), we present only the variables which are important and represent the principal factors that impact the favourites of the academic staff.

Table 7 shows the contribution of each variable in the Statements related to the material supply. From this table, we find that three items $(9,10,11)$ are important and represent the principal factors that affect the preferences of the male academic faculty in the Community College at Taibah University during the academic year 2018-2019. These three factors are: "Facilities for students with special needs available at the college; Plates and benchmarks installed to facilitate access to the various sections of the college; and There is a website for a privileged college on the internet".

Table 8 presents the contribution of each variable in the phrases related to the dependency dimension. From this table, we remark that two items $(17,18)$ are crucial and represent the principal factors that affect the preferences of the male academic faculty. These two factors are: "College offers special assistance for talented students;" and "Students are encouraged to participate in the activities of field experience".

Table 7. Contribution of Each Variable in the Statements Related to the Material Supply

\begin{tabular}{ccccccccccc}
\hline \multicolumn{10}{c}{ Contribution of each variable } \\
\hline & Fact. 1 & Fact. 2 & Fact. 3 & Fact. 4 & Fact. 5 & Fact. 6 & Fact. 7 & Fact. 8 & Fact. 9 & Fact. 10 \\
\hline 9 & 0.0983 & 0.2949 & 0.2966 & 0.2983 & 0.3000 & 0.3017 & 0.3034 & 0.3051 & 0.3069 & 0.3086 \\
\hline 10 & 0.1160 & 0.3480 & 0.3500 & 0.3519 & 0.3540 & 0.3560 & 0.3580 & 0.3600 & 0.3621 & 0.3642 \\
\hline 11 & 0.1369 & 0.4106 & 0.4129 & 0.4153 & 0.4177 & 0.4200 & 0.4224 & 0.4248 & 0.4273 & 0.4297 \\
\hline
\end{tabular}

Source: developed by the authors. 
Table 8. Contribution of Each Variable in the Phrases Related to the Dependency Dimension

\begin{tabular}{llllll}
\hline \multicolumn{7}{c}{ Contribution of each variable } \\
\hline & Fact. 1 & Fact. 2 & Fact. 3 & Fact. 4 & Fact. 5 \\
\hline 17 & 0.7467 & 2.2400 & 2.2528 & 2.2656 & 2.2785 \\
\hline 18 & 0.8811 & 2.6432 & 2.6583 & 2.6734 & 2.6887 \\
\hline
\end{tabular}

Source: developed by the authors.

Table 9 presents the contribution of each variable in the statements related to the reliability dimension. From this table, we find that two items $(23,24)$ are critical and represent the principal factors that affect the preferences of the male academic staff. These two factors are: 'The college keeps information about beneficiaries confidential;' and 'I feel proud of belonging to the college'.

Table 10 summarizes the contribution of each variable in the aspects of the social empathy dimension. From this table, we find that two items $(28,29)$ are essential and represent the main factors that affect the preferences of the male academic staff. These two factors are: 'The college is keen to identify student needs periodically;' and 'The department of the college is interested in organizing timetable in the interest of students'.

Table 9. The Contribution of Each Variable in the Statements Related to the Reliability Dimension

\begin{tabular}{llllll}
\hline \multicolumn{7}{c}{ Contribution of each variable } \\
\hline & Fact. 1 & Fact. 2 & Fact. 3 & Fact. 4 & Fact. 5 \\
\hline 23 & 0.7775 & 2.3325 & 2.3458 & 2.3592 & 2.3727 \\
\hline 24 & 0.9952 & 2.9857 & 3.0027 & 3.0198 & 3.0370 \\
\hline
\end{tabular}

Source: developed by the authors.

Table 10. The Contribution of Each Variable in the Aspects of the Dimension of Social Empathy

\begin{tabular}{llllll}
\hline \multicolumn{7}{c}{ Contribution of each variable } \\
\hline & Fact. 1 & Fact. 2 & Fact. 3 & Fact. 4 & Fact. 5 \\
\hline 28 & 0.7312 & 2.1936 & 2.2062 & 2.2187 & 2.2314 \\
\hline 29 & 0.8628 & 2.5885 & 2.6033 & 2.6181 & 2.6330 \\
\hline
\end{tabular}

Source: developed by the authors.

Table 11 summarizes the contribution of each variable in the phrases related to the dimension of enthusiasm. From this table, we find out that one item (32) is vital and represent the principal factor that affects the preferences of the male academic professionals. This factor is: "I enjoy high flexibility in my job". 
Table 11. The Contribution of Each Variable in the Phrases Related to the Dimension of Enthusiasm

\begin{tabular}{llll}
\hline \multicolumn{4}{c}{ Contributions of each variable } \\
\hline & Fact. 1 & Fact. 2 & Fact. 3 \\
\hline 32 & 0.5378 & 1.6134 & 1.6226 \\
\hline
\end{tabular}

Source: developed by the authors.

Table 12 shows the contribution of each variable in the phrases related to the dimension of dedication. From this table, it is obvious that one item (35) is very important and represent the main factor that affects the preferences of the male academic professionals. This factor is: "I have enough perseverance to work even in the worst circumstances".

Table 12. Contribution of Each Variable in the Phrases Related to the Dimension of Dedication

\begin{tabular}{llll}
\hline \multicolumn{4}{c}{ Contributions of each variable } \\
\hline & Fact. 1 & Fact. 2 & Fact. 3 \\
\hline 35 & 0.3986 & 1.1957 & 1.2025 \\
\hline
\end{tabular}

Source: developed by the authors.

Table 13 reports the contribution of each variable in the phrases related to the absorption dimension. From this table, we find out that one item (38) is vital and represent the principal factor that affects the preferences of the male academic staff. This factor is: "I feel happy to do double work".

Table 13. Contribution of Each Variable in the Phrases Related to the Absorption Dimension.

\begin{tabular}{llll}
\hline & & Contributions of each variable \\
\hline & Fact. 1 & Fact. 2 & Fact. 3 \\
\hline 38 & 0.4612 & 1.3837 & 1.3916 \\
\hline
\end{tabular}

Source: developed by the authors.

\subsubsection{Academic Staff (the Female Segment)}

Tables 14-20 present the results of the PCA relative to the questions and their items addressed to the female academic professionals in the Community College at Taibah University during the academic year of 2018-2019. In these Tables (14-20), we introduce only the items which are crucial and correspond to the principal determinants that influence the preferences of the female academic staff.

Table 14 reports the contribution of each variable in the statements related to the material supply. This table shows that three items $(9,10,11)$ are important and represent the principal factors that affect the preferences of the female academic staff in the Community College at 
Taibah University during the academic year of 2018-2019. These three factors are: 'Facilities for students with special needs available at the college'; 'Plates and benchmarks installed to facilitate access to the various sections of the college'; and 'There is a website for a privileged college on the internet'.

Table 15 shows the contribution of each variable in the phrases related to the dependency dimension. This table illustrates that two items $(17,18)$ are vital and represent the principal factors that affect the preferences of the female academic faculty. These two factors are: 'The College offers special assistance for talented students;' and 'Students are encouraged to participate in the activities of field experience'.

Table 14. The Contribution of Each Variable in the Statements Related to the Material Supply

\begin{tabular}{ccccccccccc}
\hline \multicolumn{10}{c}{ Contribution of each variable } \\
\hline & Fact. 1 & Fact. 2 & Fact. 3 & Fact. 4 & Fact. 5 & Fact. 6 & Fact. 7 & Fact. 8 & Fact. 9 & Fact. 10 \\
\hline 9 & 0.5983 & 1.7949 & 1.8051 & 1.8154 & 1.8258 & 1.8362 & 1.8466 & 1.8572 & 1.8677 & 1.8784 \\
\hline 10 & 0.7060 & 2.1180 & 2.1300 & 2.1422 & 2.1544 & 2.1667 & 2.1790 & 2.1914 & 2.2039 & 2.2165 \\
\hline 11 & 0.8331 & 2.4992 & 2.5134 & 2.5278 & 2.5422 & 2.5567 & 2.5712 & 2.5859 & 2.6006 & 2.6155 \\
\hline
\end{tabular}

Source: developed by the authors.

Table 15. The Contribution of Each Variable in the Phrases Related to the Dependency Dimension

\begin{tabular}{llllll}
\hline \multicolumn{7}{c}{ Contribution of each variable } \\
\hline & Fact. 1 & Fact. 2 & Fact. 3 & Fact. 4 & Fact. 5 \\
\hline 17 & 1.0948 & 3.2843 & 3.3030 & 3.3219 & 3.3408 \\
\hline 18 & 1.2918 & 3.8755 & 3.8976 & 3.9198 & 3.9421 \\
\hline
\end{tabular}

Source: developed by the authors.

Table 16 summarizes the contribution of each variable in the statements related to the reliability dimension. This table shows that two items $(23,24)$ are important and represent the principal factors that affect the preferences of the female academic professionals. These two factors are: 'The college keeps information about beneficiaries confidential;' and 'I feel proud of belonging to the College'.

Table 17 summarizes the contribution of each variable in the aspects of the social empathy dimension. This table shows that two items $(27,28)$ are essential and represent the main factors that affect the preferences of the female academic staff. These two factors are: "The College provides communication channels through which students can express any problem they face'; and 'The college is keen to identify student needs periodically'. 
Table 16. The Contribution of Each Variable in the Statements Related to the Reliability Dimension

\begin{tabular}{llllll}
\hline \multicolumn{7}{c}{ Contribution of each variable } \\
\hline & Fact. 1 & Fact. 2 & Fact. 3 & Fact. 4 & Fact. 5 \\
\hline 23 & 0.5993 & 1.7979 & 1.8081 & 1.8184 & 1.8288 \\
\hline 24 & 0.7671 & 2.3013 & 2.3144 & 2.3276 & 2.3408 \\
\hline
\end{tabular}

Source: developed by the authors.

Table 17. The Contribution of Each Variable in the Aspects of the Social Empathy Dimension.

\begin{tabular}{llllll}
\hline \multicolumn{7}{c}{ Contribution of each variable } \\
\hline & Fact. 1 & Fact. 2 & Fact. 3 & Fact. 4 & Fact. 5 \\
\hline 27 & 0.3967 & 1.1900 & 1.1967 & 1.2036 & 1.2104 \\
\hline 28 & 0.4681 & 1.4042 & 1.4122 & 1.4202 & 1.4283 \\
\hline
\end{tabular}

Source: developed by the authors.

Table 18 shows the contribution of each variable in the phrases related to the dimension of enthusiasm. This table shows that one item (32) is important and represent the principal factor that affects the preferences of the female academic staff. This factor is: "I enjoy high flexibility in my job".

Table 18. The Contribution of Each Variable in the Phrases Related to the Dimension of Enthusiasm

\begin{tabular}{llll}
\hline & \multicolumn{3}{c}{ Contributions of each variable } \\
\hline & Fact. 1 & Fact. 2 & Fact. 3 \\
\hline 32 & 0.3359 & 1.0077 & 1.0135 \\
\hline
\end{tabular}

Source: developed by the authors.

Table 19 shows the contribution of each variable in the phrases related to the dimension of dedication, with one item (35) being very crucial and represent the main factor that affects the preferences of the female academic personnel. This factor is: "I have enough perseverance to work even in the worst circumstances".

Table 19. Contribution of Each Variable in the Phrases Related to the Dimension of Dedication

\begin{tabular}{llll}
\hline & \multicolumn{3}{c}{ Contributions of each variable } \\
\hline & Fact. 1 & Fact. 2 & Fact. 3 \\
\hline 35 & 0.6057 & 1.8171 & 1.8275 \\
\hline
\end{tabular}

Source: developed by the authors. 
Table 20 reports the contribution of each variable in the phrases related to the absorption dimension, with one item (37) being vital and represent the principal factor that affects the preferences of the male academic professionals. This factor is: "I have spent a long time in my performance".

Table 20. The Contribution of Each Variable in the Phrases Related to the Absorption Dimension

\begin{tabular}{llll}
\hline & & Contributions of each variable & \\
\hline & Fact. 1 & Fact. 2 & Fact. 3 \\
\hline 37 & 0.5856 & 1.7567 & 1.7667 \\
\hline
\end{tabular}

Source: developed by the authors.

\subsubsection{Students}

Tables 21-24 present the results of the PCA relative to the questions and their items addressed to the students of both genders, male and female, in the Community College at Taibah University during the academic year of 2018-2019. In these Tables (21-24), we propose only the variables which are crucial and correspond to the principal contributing factor that affects the students' predilections.

Table 21 shows the contribution of each variable in the statements related to the material supply, with three items $(6,7,8)$ being important and representing the principal factors that affect the preferences of the academic staff of both genders, male and female, in the Community College at Taibah University during the academic year of 2018-2019. These three factors are: 'The College provides classrooms suitable for lectures;' 'Parking is available next to the college;' and 'The number of devices in laboratories is proportional to the number of students'.

Table 22 presents the contribution of each variable in the aspects of the social empathy dimension, with two items $(17,19)$ being crucial and representing the principal factors that affect the preferences of the academic staff of both genders, male and female. These two factors are: 'The communication between faculty and students is effective'; and 'The college is keen to identify student needs periodically'.

Table 21. The Contribution of Each Variable in the Statements Related to the Material Supply

\begin{tabular}{ccccccccccc}
\hline \multicolumn{10}{c}{ Contribution of each variable } \\
\hline & Fact. 1 & Fact. 2 & Fact. 3 & Fact. 4 & Fact. 5 & Fact. 6 & Fact. 7 & Fact. 8 & Fact. 9 & Fact. 10 \\
\hline 6 & 0.6211 & 1.8633 & 1.8739 & 1.8846 & 1.8953 & 1.9061 & 1.9170 & 1.9279 & 1.9389 & 1.9500 \\
\hline 7 & 0.7329 & 2.1987 & 2.2112 & 2.2238 & 2.2365 & 2.2492 & 2.2620 & 2.2749 & 2.2879 & 2.3009 \\
\hline 8 & 0.8648 & 2.5944 & 2.6092 & 2.6241 & 2.6390 & 2.6541 & 2.6692 & 2.6844 & 2.6997 & 2.7151 \\
\hline
\end{tabular}

Source: developed by the authors. 
Table 22. The Contribution of Each Variable in the Aspects of the Social Empathy Dimension

\begin{tabular}{llllll}
\hline \multicolumn{7}{c}{ Contribution of each variable } \\
\hline & Fact. 1 & Fact. 2 & Fact. 3 & Fact. 4 & Fact. 5 \\
\hline 17 & 0.3074 & 0.9223 & 0.9276 & 0.9329 & 0.9382 \\
\hline 19 & 0.4281 & 1.2843 & 1.2916 & 1.2990 & 1.3064 \\
\hline
\end{tabular}

Source: developed by the authors.

Table 23 presents the contribution of each variable in the phrases related to the responsiveness dimension, with two items $(21,22)$ being critical and representing the principal factors that affect the preferences of the academic staff of both genders, male and female. These two factors are: ' The faculty members are willing to answer all the students' questions'; and 'The College staff is highly motivated to serve the students'.

Table 24 summarizes the contribution of each variable in the statements related to the reliability dimension, with two items $(28,29)$ being essential and representing the main factors that affect the preferences of the male academic professionals. These two factors are: 'The college is dedicated to the students with the concepts of research ethics and scientific integrity'; and 'The college keeps information about beneficiaries confidential.'

Table 23. The Contribution of Each Variable in the Phrases Related to the Responsiveness Dimension

\begin{tabular}{llllll}
\hline \multicolumn{7}{c}{ Contribution of each variable } \\
\hline & Fact. 1 & Fact. 2 & Fact. 3 & Fact. 4 & Fact. 5 \\
\hline 21 & 0.3415 & 1.0246 & 1.0305 & 1.0364 & 1.0423 \\
\hline 22 & 0.4030 & 1.2091 & 1.2160 & 1.2229 & 1.2299 \\
\hline
\end{tabular}

Source: developed by the authors.

Table 24. The Contribution of Each Variable in the Statements Related to the Reliability Dimension

\begin{tabular}{llllll}
\hline \multicolumn{7}{c}{ Contribution of each variable } \\
\hline & Fact. 1 & Fact. 2 & Fact. 3 & Fact. 4 & Fact. 5 \\
\hline 28 & 0.4211 & 1.2632 & 1.2704 & 1.2776 & 1.2849 \\
\hline 29 & 0.5390 & 1.6169 & 1.6261 & 1.6354 & 1.6447 \\
\hline
\end{tabular}

Source: developed by the authors.

\subsubsection{Administrative Personnel}

\subsubsection{Administrative Personnel (the Male Segment)}


Tables 25-30 present the results of the PCA relative to the questions and their items addressed to the administrative personnel of both genders, male and female, in the Community College at Taibah University during the academic year of 2018-2019. In these Tables (25-30), we present only the variables which are vital and correspond to the most important factors that impact the preferences of the male administrative personnel.

Table 25 shows the contribution of each variable in the statements related to the material supply, with three items $(7,8,9)$ being important and representing the principal factors that affect the preferences of the male administrative personnel in the Community College at Taibah University during the academic year of 2018-2019. These three factors comprise: 'Facilities for students with special needs available at the college'; 'Plates and benchmarks installed to facilitate access to the various sections of the college'; and 'There is a website for a privileged college on the internet".

Table 26 presents the contribution of each variable in the phrases related to the responsiveness dimension, with two items $(16,17)$ being crucial and representing the principal factors that affect the preferences of the male administrative personnel. These two factors are: 'The team is interested in meeting the beneficiaries' requests immediately'; and 'The Advisory Council responds the students' needs quickly'.

Table 25. The Contribution of Each Variable in the Statements Related to the Material Supply

\begin{tabular}{ccccccccccc}
\hline \multicolumn{10}{c}{ Contribution of each variable } \\
\hline & Fact. 1 & Fact. 2 & Fact. 3 & Fact. 4 & Fact. 5 & Fact. 6 & Fact. 7 & Fact. 8 & Fact. 9 & Fact. 10 \\
\hline 7 & 0.5983 & 1.7949 & 1.8051 & 1.8154 & 1.8258 & 1.8362 & 1.8466 & 1.8572 & 1.8677 & 1.8784 \\
\hline 8 & 0.7060 & 2.1180 & 2.1300 & 2.1422 & 2.1544 & 2.1667 & 2.1790 & 2.1914 & 2.2039 & 2.2165 \\
\hline 9 & 0.8331 & 2.4992 & 2.5134 & 2.5278 & 2.5422 & 2.5567 & 2.5712 & 2.5859 & 2.6006 & 2.6155 \\
\hline
\end{tabular}

Source: developed by the authors.

Table 26. The Contribution of Each Variable in the Phrases Related to the Responsiveness Dimension

\begin{tabular}{llllll}
\hline \multicolumn{7}{c}{ Contribution of each variable } \\
\hline & Fact. 1 & Fact. 2 & Fact. 3 & Fact. 4 & Fact. 5 \\
\hline 16 & 0.2350 & 0.7049 & 0.7089 & 0.7130 & 0.7170 \\
\hline 17 & 0.2773 & 0.8318 & 0.8365 & 0.8413 & 0.8461 \\
\hline
\end{tabular}

Source: developed by the authors.

Table 27 presents the contribution of each variable in the statements related to the reliability dimension, with two items $(21,22)$ being critical and representing the principal factors that affect the preferences of the male administrative staff. These two factors are: 'The college keeps information about beneficiaries confidential'; and 'I feel proud of belonging to the College'. 
Table 28 summarizes the contribution of each variable in the phrases related to the dimension of enthusiasm, with one item (24) being vital and representing the principal factor that affects the preferences of the male administrative personnel. This factor is: "I accept the challenge in the tasks that I perform".

Table 27. The Contribution of Each Variable in the Statements Related to the Reliability Dimension

\begin{tabular}{llllll}
\hline \multicolumn{7}{c}{ Contribution of each variable } \\
\hline & Fact. 1 & Fact. 2 & Fact. 3 & Fact. 4 & Fact. 5 \\
\hline 21 & 0.8666 & 2.5999 & 2.6147 & 2.6296 & 2.6446 \\
\hline 22 & 1.1093 & 3.3278 & 3.3468 & 3.3659 & 3.3851 \\
\hline
\end{tabular}

Source: developed by the authors.

Table 28. The Contribution of Each Variable in the Phrases Related to the Dimension of Enthusiasm

Contributions of each variable

\begin{tabular}{llll}
\hline & Fact. 1 & Fact. 2 & Fact. 3 \\
\hline 24 & 0.5856 & 1.7567 & 1.7667 \\
\hline
\end{tabular}

Source: developed by the authors.

Table 29 shows the contribution of each variable in the phrases related to the dimension of dedication, with one item (27) being very important and representing the main factor that affects the preferences of the male administrative staff. This factor is: "I feel that the work I do has value and purpose".

Table 30 reports the contribution of each variable in the phrases related to the absorption dimension, with one item (31) being vital and representing the principal factor that affects the preferences of the male administrative staff. This factor is: "I feel happy to do double work".

Table 29. The Contribution of Each Variable in the Phrases Related to the Dimension of Dedication

\begin{tabular}{llll}
\hline \multicolumn{4}{c}{ Contributions of each variable } \\
\hline & Fact. 1 & Fact. 2 & Fact. 3 \\
\hline 27 & 0.2316 & 0.6947 & 0.6987 \\
\hline
\end{tabular}

Source: developed by the authors. 
Table 30. The Contribution of Each Variable in the Phrases Related to the Absorption Dimension

\begin{tabular}{llll}
\hline & & \multicolumn{2}{c}{ Contributions of each variable } \\
\hline & Fact. 1 & Fact. 2 & Fact. 3 \\
\hline 31 & 0.6144 & 1.8432 & 1.8537 \\
\hline
\end{tabular}

Source: developed by the authors.

\subsubsection{Administrative Personnel (the Female Segment)}

Tables 31-36 present the results of the PCA relative to the questions and their items addressed to the female administrative staff in the Community College at Taibah University during the academic year of 2018-2019. In the Tables 31-36, we give only the variables which are essential and correspond to the most crucial elements that influence the preferences of the female administrative personnel.

Table 31 shows the contribution of each variable in the statements relating to the material supply, with three items $(10,11,12)$ being important and representing the principal factors that affect the preferences of the female administrative personnel in the Community College at Taibah University during the academic year of 2018-2019. These three factors are: 'Highlyefficient administrative body available at the college'; 'Appropriate recreational activities available at the college'; and 'The college is dedicated to offer workshops training courses at the College Halls'.

Table 32 presents the contribution of each variable in the phrases related to the responsiveness dimension, with two items $(16,17)$ being important and representing the principal factors that affect the preferences of the female administrative personnel. These two factors are: 'The team is interested in meeting the beneficiaries' requests immediately;' and 'The Advisory Council responds the students' needs quickly'.

Table 33 presents the contribution of each variable in the statements related to the reliability dimension, with two items $(21,22)$ being vital and representing the principal factors that affect the preferences of the female administrative personnel. These two factors are: 'The college keeps information about beneficiaries confidential'; and 'I feel proud of belonging to the College'.

Table 34 summarizes the contribution of each variable in the phrases related to the enthusiasm dimension, with one item (25) being vital and representing the principal factor that affects the preferences of the female administrative personnel. This factor is: "I enjoy high flexibility in my job". 
Table 31. The Contribution of Each Variable in the Statements Related to the Material Supply

\begin{tabular}{lllllllllll}
\hline \multicolumn{10}{c}{ Contribution of each variable } \\
\hline & Fact. 1 & Fact. 2 & Fact. 3 & Fact. 4 & Fact. 5 & Fact. 6 & Fact. 7 & Fact. 8 & Fact. 9 & Fact. 10 \\
\hline 10 & 0.3110 & 0.9331 & 0.9384 & 0.9438 & 0.9492 & 0.9546 & 0.9600 & 0.9655 & 0.9710 & 0.9765 \\
\hline 11 & 0.3670 & 1.1011 & 1.1074 & 1.1137 & 1.1200 & 1.1264 & 1.1328 & 1.1393 & 1.1458 & 1.1523 \\
\hline 12 & 0.4331 & 1.2993 & 1.3067 & 1.3141 & 1.3216 & 1.3292 & 1.3367 & 1.3444 & 1.3520 & 1.3597 \\
\hline
\end{tabular}

Source: developed by the authors.

Table 32. The Contribution of Each Variable in the Phrases Related to the Responsiveness Dimension

\begin{tabular}{llllll}
\hline \multicolumn{7}{c}{ Contribution of each variable } \\
\hline & Fact. 1 & Fact. 2 & Fact. 3 & Fact. 4 & Fact. 5 \\
\hline 16 & 0.2325 & 0.6976 & 0.7015 & 0.7055 & 0.7096 \\
\hline 17 & 0.2744 & 0.8231 & 0.8278 & 0.8325 & 0.8373 \\
\hline
\end{tabular}

Source: developed by the authors.

Table 33. The Contribution of Each Variable in the Statements Related to the Reliability Dimension

\begin{tabular}{llllll}
\hline \multicolumn{7}{c}{ Contribution of each variable } \\
\hline & Fact. 1 & Fact. 2 & Fact. 3 & Fact. 4 & Fact. 5 \\
\hline 21 & 0.3667 & 1.1001 & 1.1064 & 1.1127 & 1.1190 \\
\hline 22 & 0.4694 & 1.4081 & 1.4162 & 1.4242 & 1.4323 \\
\hline
\end{tabular}

Source: developed by the authors.

Table 34. The Contribution of Each Variable in the Phrases Related to the Dimension of Enthusiasm

Contributions of each variable

\begin{tabular}{llll}
\hline & Fact. 1 & Fact. 2 & Fact. 3 \\
\hline 25 & 0.5587 & 1.6761 & 1.6856 \\
\hline
\end{tabular}

Source: developed by the authors.

Table 35 shows the contribution of each variable in the phrases related to the dimension of dedication, with one item (28) being very important and representing the main factor that affects the preferences of the female administrative personnel. This factor is: "I have enough perseverance to work even in the worst circumstances". 
Table 35. The Contribution of Each Variable in the Phrases Related to the Dimension of Dedication

\begin{tabular}{llll}
\hline & & Contributions of each variable & \\
\hline & Fact. 1 & Fact. 2 & Fact. 3 \\
\hline 28 & 0.5462 & 1.6387 & 1.6480 \\
\hline
\end{tabular}

Source: developed by the authors.

Table 36 reports the contribution of each variable in the phrases related to the absorption dimension, with one item (31) being essential and representing the principal factor that affects the preferences of the female administrative staff. This factor is: "I feel happy to do double work".

Table 36. The Contribution of Each Variable in the Phrases Related to the Absorption Dimension

\begin{tabular}{llll}
\hline \multicolumn{4}{c}{ Contributions of each variable } \\
\hline & Fact. 1 & Fact. 2 & Fact. 3 \\
\hline 31 & 0.4125 & 1.2375 & 1.2445 \\
\hline
\end{tabular}

Source: developed by the authors.

\section{Conclusions}

The purpose of this study was to evaluate the quality of the services offered by the Community College in Taibah University to its clients. It was worthwhile to conduct this research, the concept of satisfaction being the subject considered as the cornerstone of marketing.

A methodological approach meant to answer the initial questions that would arise before the research. The methodology is structured in two sub-steps: the first presents the techniques of data collection and the second describes techniques for processing the data collected.

Thus, the data are collected by the questionnaire technique on a sample of 281 respondents in the Community College at Taibah University during the 2018-2019 academic year. We use a descriptive analysis to show our sample and principal component analysis to determine the contribution of each variable. The principal component analysis method captures the key variables of staff satisfaction at the Community College in Taibah University of the services provided.

In the end, it emerges from this work that quality of service has become a key factor of competitiveness. The demand level of the staff increases with the level of competition which becomes more intense and the quality dominates the economic profitability. The companies that deliver quality services are then less vulnerable to a price war or any promotional action of their competitors. Otherwise, rather than seducing customers, the risk is to end up 
annoying them. In our article, the satisfaction is expressed by the factors determined by the PCA method. This study presented the satisfaction of the staff of both genders at the Community College in Taibah University by certain factors which constitute a necessity for them.

It was then that the hypotheses of this research were confined to the viewpoint that the students of Community Collage at Taibah University remained generally satisfied with the various university services.

As a result, the university is able to offer its students a quality service, to encourage them to continue their higher education in order to be more competitive in the economic and social environment. The PCA model has a positive impact on quality service in academic institutions, allowing them to assess and control the quality of their service provided. In order to guarantee a high level of satisfaction to the students, and to preserve the image of the establishment by gaining their trust.

\section{Acknowledgements}

The authors are thankful to the Editor in Chief and anonymous reviewers for their supportive and important remarks and suggestions.

\section{Formatting of Funding Sources}

The authors declare that they haven't received any funding to support their research.

\section{References}

Alsulami, H.A.J., \& Makhbul, Z.K.M. (2020). Modelling the Impact of Employment Precariousness on Employee Performance Moderated by Self Efficacy Traits. International Journal of Innovation, Creativity and Change, 11(12), 528-549. Retrieved from https://www.ijicc.net/images/vol11iss12/111236_Alsulami_2020_E_R.pdf

Alves, H., \& Raposo, M. (2007). Conceptual Model of Student Satisfaction in Higher Education, Total Quality Management, 18(5), 571-588.

Balemba, E. (2013). Evaluation of Customer Satisfaction with Services of a Micro-Finance Institution: Empirical Evidence from Women's Association for Social and Economic Gain Customers in Togo. African Journal of Marketing Management, 5(2), 26-37.

Bressolles, G., Durrieu, F., \& Giraud, M. (2007). Commercial Sites: The Influence of the Dimensions of the Electronic Quality of Service on Consumer Satisfaction and Purchase Momentum. 10th Etienne Thil Conference, CdRom.

Cantin, J., \& Rocheleau, L. (2006). Survey on the Expectations and Satisfaction of Hospitalized Users with Regard to Services Offered at Hôpital Louis-H. Lafontaine. Montreal: University of Montreal. 
Clemes, M.D., Gan, C., \& Zhang, D. (2010). Customer Switching Behavior in the Chinese Retail Banking Industry. International Journal of Bank Marketing, 8(7), 519-546.

Clemes, M.D., Gan, C.E.C. Kao, T. H., \& Choong, M. (2008). An Empirical Analysis of Customer Satisfaction in International Air Travel. Innovative Marketing, 4(1), 49-62.

Cronin, J.J.J., \& Taylor, S. A. (1992). Measuring Service Quality: A Re-examination and Extension. Journal of Marketing, 56, 55-68.

Cronin, J., Brady, M., \& Hult, G. (2000). Assessing the Effects of Quality, Value, and Customer Satisfaction on Consumer Behaviour Intentions in Service Environments. Journal of Retailing, 76(2), 193-218.

Fouquereau, E., Froment, B., Fazilleau, L., \& Baudouin, A. (2006). Over the Course of the Course: Satisfaction and Dissatisfaction of "L" Students towards the University between 2001 and 2004. Tours: Université François -Rabelais de Tours, Observatory of Student Life No. 4.

Gauthier, B. (2001). Measuring Customer Satisfaction to Better Meet his Expectations. Quebec: Réseau Circum Inc.

Gonzalez, L. (2004). Pilot Study on the Implementation and Perceptions of ICT. Geneva: University of Geneva.

Ilunga, F. (2011). Customer Satisfaction of Financial Institutions: Comparative Analysis of Client Satisfaction of Commercial Banks and Microfinance Institutions. Bukavu, DRC: Unpublished Memory, Faculty of Economics and Management, UCB Bukavu.

Jouandeau, A. (2004). Contribution to the Modeling of Customer Satisfaction by Fuzzy Logic. Lyon: National Institute of Applied Sciences.

Le Roy, C. (2004). Student Behavior in the Mobile Phone Market: Inertia, Captivity or Fidelity? LARGE, Paper No. 66. Strasbourg: LARGE.

Lewis, R.C. (1987). The Measurement of Gaps in the Quality of Hotel Services. International Journal of Hospitality Management, 6(2), 83-88.

Madden, J. (2017). Four Pillars to Building a Positive School Culture. International Journal of Innovation, Creativity and Change, 3(2), 33-38. Retrieved from https://www.ijicc.net/images/vol3iss2/Madden_2017.pdf

Moore, B. M. (1987). Individual Difference and Satisfaction with Teaching. Paper Presented at the Annual Meeting of the American Educational Research Association. Washington, D.C.: ERIC Document Reproduction Service No. ED282851.

Moutte, J. (2007). The Impact of Client-facing Staff on Customer Satisfaction: Proposed Conceptual Model. Center for Studies and Research on Organizations and Management, W.P. no 782. Marseille: Center for Studies and Research on Organizations and Management.

Nguyen, T. (2012). Measurement of Quality of Service in Higher Education in Vietnam. Vietnam: Faculty of Business Administration, University Institute of Technology, Post and Telecommunications.

Omar, N. A., Nazri, M. A., Abu, N.K., \& Omar, Z. (2009). Parents' Perceived Service Quality, Satisfaction and Trust of a Childcare Centre: Implication on Loyalty. International Review of Business Research Papers, 5(5), 299-314. 
Park, J. (2007). The Determinants of Visitor Satisfaction and Loyalty Attending the National Museum of Contemporary Art in South Korea. South Korea: Academy of Nantes, Faculty of Law, Economics and Management, University of Angers.

Rorer, L.G. (1983). "Deep" RET: A Reformulation of Some Psychodynamic Explanations of Procrastination. Cognitive Therapy and Research, 7, 1-10. https://doi.org/10.1007/BF01173419

Sempels, C. (2005). The Intangibility of a Global Offer of Services: Conceptualization, Operationalization, Variables of Influence and Impact on the Level of Perceived Risk. Leuven: Faculty of Economic, Social and Political Sciences, Catholic University of Louvain.

Sultan, P., \& Wong, H.Y. (2010). Service Quality in Higher Education: A Review and Research Agenda. International Journal of Quality and Service Sciences, 2(2), 259-272.

Tran, K.T., Nguyen, P.V., Nguyen, T.D., \& Ton, U.N.H. (2020). The Impact of Organisational Commitment on the Relationship between Motivation and Turnover Intention in the Public Sector, International Journal of Innovation, Creativity and Change, 11(12), 1-25. Retrieved from https://www.ijicc.net/images/vol11iss12/111201_Tran_2020_E_R.pdf

Tremblay, P., \& Beauregard, B. (2006). Application of the Tétraclasse Model to the Survey Results of a Public Body: The Case of the Régie des Rentes du Québec. Québec: Center of Expertise for Large Organizations.

Tremblay, P. (2006). Measuring Customer Satisfaction and Expectations: From Classic Models to Asymmetric Models. Québec: Center of Expertise for Large Organizations.

Vanhamme, J. (2001). Transaction-Specific Consumer Satisfaction: Definition, Antecedents, Measurement and Modes. Leuven: LABACC / Fucam, Katholieke Universiteit Leuven. 